\title{
A PERCEPÇÃO DOS FIÉIS PENTECOSTAIS QUANTO AO ENVOLVIMENTO DE SUAS DENOMINAÇÕES NA ATIVIDADE POLÍTICA.
}

\author{
Valdir Pedde ${ }^{l}$
}

Resumo: $\mathrm{O}$ artigo realiza um estudo exploratório sobre a forma com que os participantes da Igreja Universal do Reino de Deus, Igreja do Evangelho Quadrangular e Assembléia de Deus percebem as eleições e a postulação de seus representantes a cargos políticos. Verificou-se que há uma grande aceitação por parte dos fiéis dessas igrejas. A pesquisa revelou que a cosmologia é uma variável fundamental na relação entre fiéis (religião) e política. Quanto mais uma deno minação acionar recursos mágicos através de rituais, maior será sua possibilidade de alcançar seu objetivo no campo político. Por fim, essa realidade tende a mostrar que a interpretação do processo de secularização, enquanto avanço da racionalidade científica e o recuo da religião, entendida como subjetivação do sagrado, deve ser repensada.

Palavras-chave: Pentecostalismo, religião, magia, política, eleições.

Keywords: Pentecostalism, religion, magical, politics, elections.

\section{INTRODUÇÃO}

Este texto resulta de um estudo exploratório entre fiéis da Igreja Assembléia de Deus, da Igreja do Evangelho Quadrangular e da Igreja Universal do Reino de Deus. O objetivo é avaliar como tem sido percebido pelos freqüentadores dos cultos o envolvimento destas denominações ${ }^{2}$ com a política.

${ }^{1}$ Doutorando em Antropologia Social, Universidade Federal do Rio Grande do Sul.

2 Para fins desse trabalho, usamos o termo denominação como sinônimo de Igreja, enquanto instituição. 
Este estudo exploratório baseia-se em uma pesquisa realizada entre 66 evangélicos pentecostais. Destes, 25 pertencem à Assembléia de Deus (AD), 19 são da Igreja do Evangelho Quadrangular (IEQ) e 22 da Igreja Universal do Reino de Deus (IURD). Nesta pesquisa, procuramos obedecer dois critérios. O primeiro deles foi não realizá-lo somente em Porto Alegre mas também em algumas cidades da Grande Porto Alegre. O segundo critério foi o de não utilizar as últimas eleições para o legislativo municipal como material para a pesquisa. A razão para tal, como veremos no decorrer do texto, é a de que buscamos averiguar se os fiéis acompanham o mandato parlamentar daqueles que elegem. Em lugar de verificar o grau de envolvimento com as últimas eleiçóes, centramos nossa pesquisa no grau de conhecimento dos fiéis sobre a prática parlamentar dos eleitos para o legislativo estadual há dois anos.

\section{A RELAÇÃO ENTRE RELIGIÃO E POLÍTICA}

Quando os membros das denominações pesquisadas foram perguntados acerca de sua opinião sobre a participação de suas igrejas na política institucional, 89\% deles afirmaram tratar-se de uma atitude benéfica para suas instituiçóes religiosas. Apenas 5\% não percebiam essa atividade como benéfica e $6 \%$ não tinham opinião formada a respeito.

$\mathrm{Na}$ Assembléia de Deus, encontra-se o índice mais alto de aprovação dessa relação. $92 \%$ dos membros percebem a relação entre sua denominação e a política como benéfica e apenas $4 \%$ não a vêem como conveniente. $\mathrm{Na}$ IURD, são $90 \%$ os que manifestaram aprovação. Apenas $5 \%$ deles não concordam com essa interação. Na IEQ, 89\% entendem como benéfica a relação, sendo $11 \%$ aqueles que não a aprovam entre a IEQ e a política. Nesta questão somente uma pessoa $(5,5 \%)$ disse que não saberia responder.

Seguem-se algumas opiniōes favoráveis à interação entre religião e política. Com poucas variações nas formulações representam as idéias mais citadas nas entrevistas:

"Talvez não diretamente [benéfica] para a religião, mas às pessoas como um todo”. 
"É benéfico não só aos evangélicos, mas à sociedade que procura pessoas honestas e capazes de seguirem princípios".

"Eu acho muito importante, pois nós, evangélicos, temos que estar sempre bem informados em relação a nossa política. Aumenta a consciência política e faz o povo chegar mais a Deus".

Percebe-se que a ética (a moral referente à religiosidade assumida) é a porta de entrada das comunidades pentecostais para o mundo da política. Uma questão que se levanta é: quais são as questões que integram a cosmovisão dess a moralidade que se preocupa com a vida política institucional? Com exceção da maioria dos pastores da $\mathrm{AD}$, podemos observar que a IEQ e a IURD usam o discurso da batalha espiritual como elemento fundamental para o discurso interno, ou seja, para o convencimento de seus fiéis a votarem em seus candidatos.

Transparece a concepção pentecostal da política como um espaço de corrupção e de vilania, constituindo-se em um lugar onde o mal atua e precisa ser "resgatad o por Deus". Para uma das pessoas entrevistadas, filiada à IURD, "de $100 \%$ dos políticos não evangélicos, $99 \%$ são corruptos. De $100 \%$ evangélicos, $0,5 \%$ são corruptos”. Essa concepção cosmológica de batalha espiritual e esse instrumental lingüístico de percepção do religioso sobre a esfera política já foi anteriormente estudada por Oro (2001).

Uma pessoa da $\mathrm{AD}$ que não percebe como benéfica a interação entre sua denominação e a política disse: "Correria o risco dessa pessoa se corromper e assim perderia a graça de Deus”. Neste caso, a política institucionalizada é percebida como perigosa. A política enquanto tal é entendida como um espaço propício para a corrupção. Se o cristão envolverse com a política e "cair em tentação", poderia afastar-se da fé.

Aqui vale a pena notar a distinção entre os discursos de membros da $\mathrm{AD}$ e da IURD. Enquanto os participantes desta última instituição tendem a usar um discurso vinculado à batalha espiritual, entre os fiéis da $\mathrm{AD}$, a política constitui-se em um espaço de possibilidade de "perda da graça de Deus". A disti nção en tre os dois discursos é sutil, mas certamen te gera comportamentos diferentes em relação à política. Para os participantes da IURD, a política é um espaço do mal, demoníaco, e que deve ser "resgatado para 
Deus". Todavia, para alguns fiéis da $\mathrm{AD}$, a política consiste em um espaço de maior provação para o cristão. ${ }^{3}$ Assim sendo, deveria ser evitado para o bem espiritual do postulante ao cargo público. Essas duas formas de ver a política sugerem que há posturas diferenciadas quanto à recepção das recomendações dos pastores de que os fiéis votem nos candidatos por eles indicados. Desta forma, entre outros aspectos, as diferentescosmovisóes religiosas sugerem posturas diferenciadas ante o exercício do votar.

Constata-se, portanto, que as instituições religiosas pesquisadas partem de um mesmo princípio, qual seja, o de que a relação dos cristãos com o mundo é complicada e desvantajosa para os fiéis. Mas, deste princípio comum, surgem duas diferentes atitudes.

A primeira e, aparentemente mais aceita, é a convicção de que a relação do cristão com o mundo (neste caso, com a política) deve ser aprofundada. Este contato é entendido como benéfico para as igrejas que mantêm os políticos a elas ligados, e para a sociedade como um todo, já que esses homens públicos são identificados como honestos e pessoas de princípios. A segunda postura frente à relação entre religião e política é a percepção desse contato como sendo uma armadilha para a vida do cristão. A pesquisa realizada mostra que esta última postura é minoritária. Para os entrevistados que sustentam essa última posição, o fiel deve abster-se de imiscuir-se na política, identificada como um lugar de corrupção e grandes tentações.

Em um momento próximo da pesquisa aprofundaremos e estenderemos com mais dados quantitativos e qualitativos este tópico. De qualquer forma, parece-nos paradoxal a forma como os membros, sobretudo da AD, vêem a relação entre religião e política. Por um lado, temos que $92 \%$ dos fiéis entrevistados entendem ser positiva esta relação, mas, neste último pleito para o legislativo municipal, a $\mathrm{AD}$ não conseguiu eleger nenhum de seus candidatos. Será apenas porque seus votos se pulverizam entre muitos

\footnotetext{
${ }^{3}$ Essa percepção foi revelada não apenas por quem discordava da interação entre as duas esferas estudadas, mas também por alguns que percebiam essa relação como benéfica.
} 
candidatos? Ou será que a alegada percepção de que a relação entre religião e política é benéfica não consiste em uma convicção realmente? Enfim, merece ser mais explorado até que ponto a cosmovisão religiosa pregada nas distintas denominações influencia suas posturas diante das eleições. A postura frente às urnas depende da cosmovisão que a instituição religiosa passa a seus fiéis com respeito à relação entre o cristão e o mundo que a rodeia? Trata-se de questóes que merecem uma pesquisa mais aprofundada.

De qualquer forma, permanece válida a sugestão de Ari Pedro Oro (2001b), para quem o sucesso ou não nos pleitos eleitorais está intimamente ligado à estrutura hierárquica das denominaçóes. Quanto mais hierárquica e vertical (a IURD) é colocada a nominata de representantes da instituição religiosa, mais sucesso obtém nas urnas. $\mathrm{A} A \mathrm{D}$, que conta com uma estrutura mais congregacional, horizontal e democrática, é a que menos sucesso vem obtendo na conquista de vagas nos legislativos, ao menos no Rio Grande do Sul.

\section{COMO OS EVANGÉLICOS PENTECOSTAIS ACOMPANHAM SEUS CANDIDATOS}

Constatamos que, de um modo geral, os evangélicos pentecostais apresentam uma compreensão positiva sobre a relação entre religião e política (89\%). Por outro lado, veremos que esses fiéis não acompanham efetivamente os trabalhos desses religiosos-políticos por eles eleitos. Temos que $74 \%$ dos entrevistados sabem da existência de deputados estaduais ligados à sua denominação religiosa. Contudo, esse número sofre um decréscimo quando relacionado aos fiéis que efetivamente sabem nominar os políticos ligados ao campo pentecostal: $42 \%$. Essa tendência de queda confirma-se quando os fiéis são questionados a respeito das realizaçóes desses políticos. $33 \%$ dos entrevistados sabiam declarar alguma realização feita por políticos evangélicos. Conclui-se que 1/3 dos fiéis presta alguma atenção àquilo que seus representantes fazem na Assembléia Legislativa. 


\section{Quadro 1}

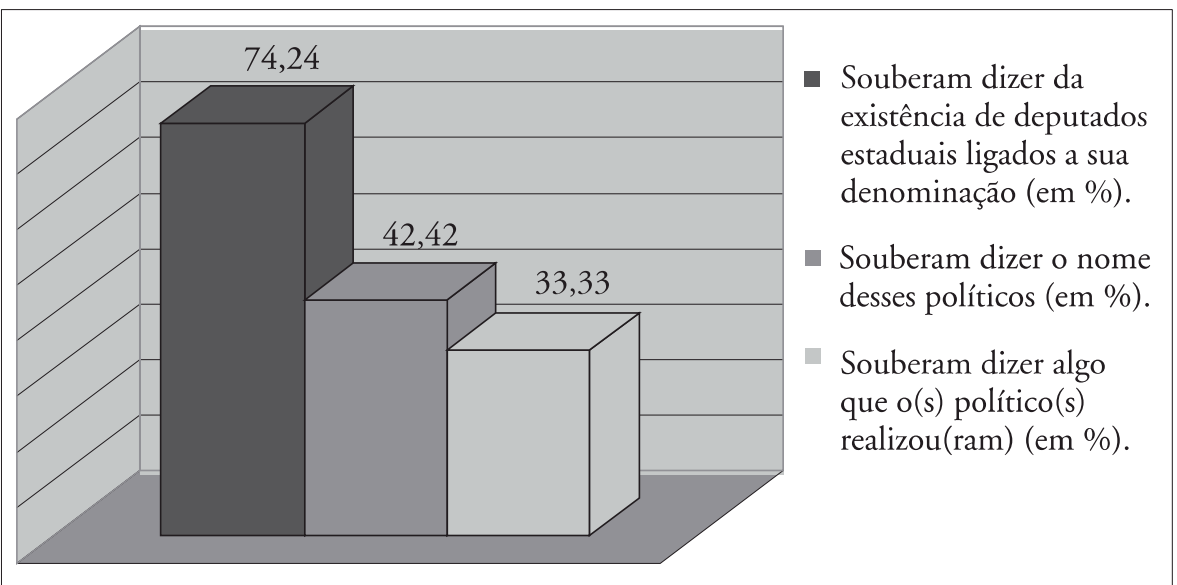

Para efeitos de comparação, uma pesquisa realizada em Santa Catarina revelou que 23\% do eleitorado lembra em quem votou para deputado estadual (Loetz, 1998). Já em São Paulo, uma pesquisa Datafolha mostrou que $72 \%$ dos entrevistados não se lembram em quem votaram para vereador na última eleição (Marinheiro, 2000). Diante destes números, podemos dizer que o eleitorado das denominações pesquisadas supera a média. ${ }^{4}$ Mesmo assim, os índices levantados entre os pentecostais podem ser considerados baixos, uma vez que $89 \%$ deles percebem as candidaturas de evangélicos como benéficas para suas igrejas e/ou sociedade. A partir desse dado, poder-se-ia pressupor uma relação mais estreita entre religiosos-políticos e eleitorado, já que o universo de possibilidades de candidatos a serem votados se restringe a um ou dois nomes por denominação.

\footnotetext{
${ }^{4}$ Devemos lembrar que a pesquisa Novo Nascimento (1996) constatou a baixa participação cívica entre os evangélicos, mas considerada semelhante ao da população em geral. Contudo, a relação entre evangélicos da região metropolitana do Rio de Janeiro e seus representantes políticos foi expressivamente mais intensa do que a da população em geral.
} 
A partir do quadro 1, podemos formular duas observações, complementares entre si. A primeira é a de que os evangélicos não assumem muito mais suas posturas de cidadãos do que a grande maioria do povo brasileiro. Sabe-se que a relação de cobrança do eleitor sobre o eleito é pequena (Fernandes, 1996). As denominações também não entendem como sendo de sua alçada acompanhar de perto a prática parlamentar dos deputados por elas eleitos. Como afirma o deputado estadual do Rio Grande do Sul, Sérgio Peres (PL), da IURD, "tem projetos que eu faço que a igreja nem tá sabendo". O objetivo das denominaçóes, portanto, como a maioria das organizações, é de ter alguém que os represente nos meios políticos a fim de que, quando elas necessitarem, possam contar com eles como supostos porta-vozes. Mesmo assim, se comparados com a população brasileira, talvez seja possível dizer que, nesse quesito, a afinidade religiosa entre as fiéis e os políticos por eles eleitos motiva um acompanhamento maior da prática parlamentar que o eleitorado brasileiro em geral. A pesquisa Novo Nascimento (Fernandes, 1996) mostra essa mesma tendência. Afinal, em nossa pesquisa, 33\% dos entrevistados sabiam dizer algo sobre projetos defendidos pelos deputados estaduais por eles eleitos. Qual será a percentagem de cidadãos brasileiros que sabem relatar algum dos projetos defendidos por seus candidatos?

A segunda observação a ser assinalada é que os pentecostais pesquisados que acompanham os candidatos por eles eleitos, referiram-se apenas aos projetos que dizem respeito às questões de moral. ${ }^{5}$ Certamente, se algum desses deputados votasse a favor de alguma lei contrária à cosmovisão da moral religiosa de sua denominação, rapidamente os fiéis o saberiam e o questionariam. Por conseguinte, os evangélicos dessas denominaçôes, ao acompanharem o desempenho dos religiosos-políticos, não o fazem se não em nível de controle sobre as questões morais-religio-

\footnotetext{
${ }^{5}$ Entre outros pesquisadores, Coradini (2001) já havia assinalado a moral religiosa como princípio de legitimação para as candidaturas tanto das organizaçóes religiosas como de seus representantes.
} 
sas. Este é o específico para o qual, para eles, justifica-se a existência de evangélicos -políticos. Para os participan tes destas denominaçôes, a questão da moral religiosa é de grande relevância. Do universo pesquisado, $86 \%$ consideraram essencial a presença de uma moral religiosa no exercício parlamentar.

Como vimos no quadro 1 , apenas $33 \%$ dos entrevistados sabiam dizer algo acerca do que os religiosos-políticos haviam realizado como deputados estaduais. Entretanto, nem sempre as respostas estavam relacionadas diretamente à prática política. Do universo de 33\%, mais da metade $(54,4 \%)$ lembraram de aspectos não diretamente ligados ao fazer político, como, por exemplo: ajuda médica a familiares; doação financeira para reforma de templos; auxílio a programas denominacionais de recuperação a dependentes químicos; auxílio financeiro a escolas de vilas empobrecidas, entre outras. Por conseguinte, 45,6\% dos entrevistados lembraram de aspectos diretamente ligados ao trabalho parlamentar. Em outras palavras, isso significa dizer que $15 \%$ do universo pesquisado citou projetos ou leis encaminhadas por esses deputados.

Além disso, pode-se perceber que, em grande parte, a relação estabelecida entre fiéis e políticos é clientelis ta. Freqüentando os gabinetes dos deputados estaduais dos mais diversos partidos e de pessoas ligadas ou não a alguma instituição religiosa, foi possível perceber uma afluência de pedintes dos mais diversos matizes. Estabelece-se, então, uma relação assistencial-clientelista. Como vimos acima, muitas das questôes lembradas pelos fiéis como realizações importantes dos religiosos-deputados situa-se naquilo que Machado (2003) denominou de "clientelismo corporativista".

Vimos no quadro 1 que 74,2\% dos entrevistados sabiam da existência de deputados ligados a sua denominação religiosa, e que 33,3\% deles conheciam alguma realização ou os projetos defendidos por estes religiosospolíticos. Mas vejamos como esses dados estão distribuídospor denominação religiosa, ou seja, verifiquemos como os fiéis de cada uma das denominações respondeu a essa questão. 
Tabela 1

\begin{tabular}{|c|c|c|}
\hline Denominaçóes & Sim & Não \\
\hline Igreja Universal do Reino de Deus & 77,3 & 22,7 \\
\hline Assembléia de Deus & 76 & 24 \\
\hline Igreja do Evangelho Quadrangular & 68,4 & 31,6 \\
\hline
\end{tabular}

Com relação à IURD, aqui se levanta um dado curioso. Segundo a pesquisa Novo Nascimento de 1996, no Rio de Janeiro, 88\% dos fiéis da IURD ignoravam a presença de pastores em cargos políticos. Na Grande Porto Alegre, 77,3\% dos entrevistados desta denominação disseram saber da existência de deputados ligados a sua denominação religiosa. Contudo, apenas 13,6\% sabiam dizer o nome desse político. Ou seja, 86,4\% desses entrevistados não sabem dizer o nome desses políticos. Esse dado mostra-se compatível com a pesquisa Novo nascimento. Desta maneira, podemos dizer que, hoje, os fiéis da IURD sabem que sua denominação tem se preocupado em levar à cena política representantes de suas fileiras. Contudo, pode-se concluir que esses fiéis não se preocupam em acompanhar o trabalho dos religiosos-políticos, como veremos na tabela 2 .

Tabela 2

\begin{tabular}{|c|c|c|}
\hline Denominaçóes & Sim & Não \\
\hline Assembléia de Deus & 56 & 44 \\
\hline Igreja do Evangelho Quadrangular & 31,2 & 68,8 \\
\hline Igreja Universal do Reino de Deus & 4,54 & 95,46 \\
\hline
\end{tabular}

Comparando as tabelas 1 e 2, verificamos que os membros da $\mathrm{AD}$ possuem o maior índice de conhecimento sobre as realizações dos deputados que ajudaram a eleger, enquanto a IURD, com significativa diferença, o menor índice de conhecimento. Na prática, a relação entre saber sobre a existência de políticos ligados a sua denominação e ter conhecimento sobre 
algo que esses políticos realizaram em seus mandatos é praticamente inversa. Se a IURD é a denominação em que os membros mais sabem sobre a existência de políticos a ela filiados, é também ela que apresenta o menor grau de interação e de conhecimento dos membros acerca da prática parlamentar dos eleitos.

Se a IURD consegue o maior grau de adesão de seus membros para eleger seus candidatos, $95 \%$ conforme a pesquisa Novo Nascimento (1996), em contrapartida, parece ser ela a que "conduz" seus membros a u m menor interesse pelas questões da política. Apenas 4,5\% lembravam de algo realizado pelo religioso-político.

Entre as denominações pesquisadas a $\mathrm{AD}$ apresenta o maior índice de conhecimento sobre o exercício parlamentar por ela eleitos. Dos entrevistados dessa denominação, 76\% sabiam da existência de deputados estaduais ligados a sua denominação e $56 \%$ souberam citar algo que seus representantes legislativos haviam realizado.

Conforme Oro (2001), essa denominação possui, entre as três, a estrutura mais democrática. $\mathrm{O}$ inverso mostra-se igualmente verdadeiro. Ou seja, na IURD, a estrutura é mais verticalizada e hierárquica, sendo onde seus membros menos sabem a respeito dos políticos eleitos. No entanto, não parece haver relação com os meios comunicacionais. Sem dúvida, a estrutura e as possibilidades de comunicação entre a hierarquia da IURD e os seus membros são muito maiores do que a $\mathrm{AD}$ ou IEQ, o que talvez explica o fato de seus membros saberem mais sobre a existência de religiosos-políticos. Contudo, isto não fornece subsídios para explicar a razão de os participantes dessa denominação serem os mais desinformados em relação aos políticos por ela eleitos. A Folha Universal, por exemplo, possui um espaço específico para tratar de questôes políticas ligadas a sua denominação e às bandeiras levantadas pelos políticos a ela filiados.

Uma interpretação para essa questão, já acima colocada, é a sugestão de Oro (2001b) sobre a influência das organizações religiosas no sucesso eleitoral. Em seu entender, a estrutura com que essas denominações se apresentam influencia profundamente a relação que seus membros possuem com a política. Nossa sugestão é que, juntamente com a influência do tipo 
organizacional sobre a forma pela qual seus membros votam, pesa igualmente a cosmovisão pregada pela denominação. Aliás, esta referência à importância cosmológica sobre a forma de votar dos fiéis destas denominações não está ausente na hipótese interpretativa de Ari P. Oro (2001b). Para este autor, a cosmologia está submetida à lógica organizacional, ou seja, ao "poder carismático da IURD” (Oro, 2001b, p. 57). Assim, a cosmologia seria uma variável dependente. Essa é uma hipótese engenhosa e, como bem notou Carlos Alberto Steil (2001), de grande valor heurístico. Enfim, é nessa linha analítica que nos inscrevemos, mas dando especial atenção a variável cosmológica. Esse é o tema do próximo ponto.

\section{UMA COSMOVISÃO MÁGICA CONDUZ A UM MAIOR ATIVISMO-CONFORMISTA?}

Como vimos anteriormente, os fiéis da IURD mostram-se os mais cientes da existência de deputados ligados a sua denominação. Mas, por outro lado, quais serão os fatores que levam os fiéis da IURD a serem os menos inteirados sobre a prática parlamentar de seus representantes?

Conforme o estudo de Oro (2001), sabe-se que a IURD é a denominação mais hierárquica e melhor organizada em busca de seus objetivos políticos. Sabidamente é também uma das denominações que mais faz uso da magia ${ }^{6}$ (Oro, 2001a). A IURD constitui-se na denominação, entre as três pesquisadas, que mais se utiliza de recursos mágicos. $\mathrm{Ou}$, como afirma Barros (1995), a IURD consiste em uma denominação sacramental. Em

\footnotetext{
${ }^{6}$ Religião e magia, como não poderiam deixar de ser, são conceitos típico-ideais, uma vez que, na realidade social, esses dois elementos estão misturados em diferentes intensidades. Além disso, não devemos esquecer que Bourdieu (1992) afirmou que a distinção entre religião e magia tem maior relação com o poder e com a ideologia do que com a ciência. Para ele, a oposição entre religião e magia "dissimula a oposição entre diferenças de competência religiosa que estão ligadas à estrutura da dist ribu ição do capital cul tural” (Bourdieu, 1992: 44). Contudo, não devemos nos ater apenas a essa conceituação.
} 
contrapartida, os dados aqui apresentados mostraram que é na IURD que encontramos os participantes menos informados ou inteirados sobre a prática dos religiosos-políticos da denominação. Como explicar essa relação? Procurando aclarar essa questão partiremos da análise weberiana sobre os fenômenos religiosos.

Da concepção geral de Weber aprendemos que a racionalização pela ética religiosa, complementada pela racionalização científica, desencantou o mundo, ou seja, desmagicizou o mundo da vida. Para o sociólogo alemão, as religiosidades mágicas tendem a desvalorizar a ação no mundo já que "ligam a decisão sobre a salvação ao êxito de processos racionais não cotidianos" (Weber apud Pier ucci, 2003, p. 48). Em outras palavras, a atividade mágica é ligada aos processos racionais, mas que estão fora da esfera cotidiana. A magia impede a percepção das relaçôes entre causa e efeito na sociedade. ${ }^{7}$ Em virtude disso, essas religiosidades tendem a desvalorizar a ação no mundo.

A magia é considerada por Weber um processo racional, mas que não produz uma racionalização de conduta de vida, isto é, uma ética. Não é, assim, passível da produção de uma racionalização teórico-prática, somente prática-técnica. ${ }^{8}$ Para Weber, as representaçôes mágicas possuem um caráter subjetivamente mais racional com relação a fins do que o comportamento religioso. A magia está totalmente voltada para o aqui e o agora. Daí sua percepção sobre a religião-mágica ser de cunho utilitarista e instrumental. Contudo, essa religiosidade busca respostas da ordem do extra-cotidiana, isto é, as respostas não são objetivamente racionais. A magia sempre possui um objetivo muito prático e suas expectativas com os resultados são

\footnotetext{
7 Um estudo interessante e de recapitulação sobre as principais teorias sobre ritos nos é acessível através do livro de Segalen (2002). Uma das características do rito é que este conduz as pessoas a esperarem uma eficácia que "não advém de uma lógica puramente empírica que se esgotaria na instrumentalidade técnica da liga ção causa-efeito” (p. 32).

${ }^{8}$ A racionalidade teórico-prática é o tipo de racionalização exercida pela ciência, enquanto a racionalidade prática-técnica, não estabelece correlaçôes de racionalidade objetiva, ou seja, não estabelece relação empírica entre causa e efeito.
} 
as mais imediatas possíveis. A reflexão sobre os meios constitui-se em algo secundário, ou seja, a relação "meio-fins é subjetivamente avaliada" e não de forma teórico-sistêmica (Schluchter apud Pierucci, 2003, p. 80).

Como Weber também nos ensinou, quando interpretamos uma realidade social, não é possível deixar de lado os aspectos simbólicos (apud Souza, 1999). Ao analisarmos um fenômeno social como a religião, esta questão torna-se ainda mais fundamental. $\mathrm{Na}$ relação entre religião e política, por exemplo, não convém nos atermos apenas aos mecanismos básicos que se movimentam no mundo da política. Convém incluir, também, a percepção desse fenômeno como algo cultural, como um sistema de escolhas, o que certamente ultrapassa uma leitura da realidade pela lógica da "razão prática”. As cultu ras são sistemas simbólicos e não apenas a escolha racional entre meios e fins. Em outras palavras, não podemos deixar que a percepção utilitarista e instrumental da religião oblitere a visão dos aspectos simbólicos que a compóe. Ao deixarmos de lado a simbologia impregnada nas relações sociais, "legitimamos como oficiais as ideologias da ciência que nos remetem ao con trole da natureza" (DaMatta, 2001, p.16).

Como muito bem colocou Ari Pedro Oro, a partir de uma cosmovisão mágica não há situação ou problema

que não possa ser abarcado pelo sobrenatural, assim como não há situação que não se relacione, ao menos em parte, com o sagrado; não há, também, situações em que a medicina, a economia, ou a física, constituam cursos de ações excludentes da religião. Segundo esta ótica, não há utilitarismo na conduta mágica, pois não se vive a ruptura de planos entre o céu e a terra; não há carreira oportunista de idas e vindas relativamente à religião, antes um recurso explicativo vinculado a uma visão de mundo totalizante, segundo a qual todo o mal e todo o bem se iniciam no plano místico (Oro, 2001a, p. 81).

Parece-nos ser exatamente esse o caso da IURD. Não há uma ética unificadora da conduta, ou seja, um princípio valorativamente racional que submeta a todas as realidades, mas apenas conforma-se a uma moral culturalmente valorizada. Essa moralidade identifica-se com uma moralidade cristã difusa e conservadora com relação a questôes como a contrariedade 
ao aborto e ao casamento entre homossexuais, a proteção à propriedade privada, etc. Com raríssimas exceções, o posicionamento de seus políticos é notadamente conservador. Justamente por sua cosmovisão mágica, suas respostas nos campos em que ela se lança são bem sucedidas. A rigor, não lhes interessam os meios, mas os resultados. Evidentemente, essa estratégia tem certas limitaçôes que precisam ser respeitadas, como, por exemplo, a cultura na qual está inserida. ${ }^{9}$ Sua estratégia de batalha espiritual levada ao discurso político, por exemplo, oferece essa possibilidade. O próprio sucesso, pessoal, institucional ou político, é inserido dentro da dinâmica mágicodiscursiva. Essa dinâmica, pelo menos até agora, tem transformado fiéis em ativos cidadãos-votantes que procuram concretizar no aqui e agora um projeto cosmológico e religioso em uma realidade tangível, através da esfera política, portanto, através da imanência. Esse ativismo, por obedecer à lógica mágica, não consegue ultrapassar posicionamentos conservadores. Assim, essa religiosidade tende a desvalorizar a ação no mundo por não perceber a relação de causa e efeito em processos cotidianos. Para eles, o processo entre causa e efeito está vinculado a processos extracotidianos, daí a necessidade de ritualização de praticamente todas as suas ações, e, conforme nos ensina Weber, essa racionalidade é clara e objetiva com relação a fins. Talvez esteja aí a explicação através da qual se pode compreender uma alta taxa de compromisso entre fiéis da IURD para a votação nos candidatos indicados pela instituição e, igualmente, a baixa percentagem de acompanhamento dos fiéis aos seus respectivos representantes políticos. Uma vez colocados os "representantes de Deus" nas institu içôes políticas, a transformação esperada da realidade ocorrerá como em um "passe de mágica".

\footnotetext{
${ }^{9} \mathrm{Ou}$, como preferia Leach (1978), a magia trata o símbolo como sinal, transforma o metafórico em metonímico. Para este antropólogo, o símbolo é tudo o que representa uma ausência, o abstrato ou o futuro. $\mathrm{O}$ sinal, em contrapartida, conduz a um efeito imediato, a certo tipo de comportamento. Mas Leach considera que isso somente é possível nas sociedades onde há uma forma convencional de hábitos, isto é, onde muitas vezes os símbolos são tratados como sinais.
} 
Se os fins assumidos pelas instituições religiosas em relação à política pudessem ser enquadrados numa ação da ordem da razão prática, a ação cultural e simbólica na qual ela está embebida nos aponta para questôes muito mais amplas e complexas. O ritualismo mágico encontra um fértil campo para sua atuação, já que a ritualização ajuda a re-ordenar a percepção sobre a realidade social. "Os ritos possuem a possibilidade de criar um universo único e coerente no plano simbólico" (Douglas apud Segalen, 2002, p. 30). Disto podemos concluir que a racionalidade política acaba por ser submetida à lógica mágico-religiosa. Além disso, percebe-se que a religião sai de uma subjetivação individual para alcançar com objetividade a esfera pública. A religiosidade e a religião, enfim, tomaram uma dimensão mais ampla e complexa do que apenas a da subjetividade.

\section{REFERÊNCIAS}

BARROS, Mônica do Nascimento. A Batalha do Armagedom: Uma Análise do Repertório Mágico-Religioso Proposto pela Igreja Universal do Reino de Deus. 1995. 203 f. Dissertação (Mestrado em Sociologia) - Programa de Pós-Graduação em Sociologia, Universidade Federal de Minas Gerais, Belo Horizonte.

BOURDIEU, Pierre. A Economia das Trocas Simbólicas. 3.ed. São Paulo: Perspectiva, 1992.

CORADINI, Odaci Luiz. Em Nome de Quem? Recursos sociais no recrutamento de elites políticas. Rio de Janeiro: Relume-Dumará, 2001.

DAMATTA, Roberto. Vendendo totens: prefácio parazeroso para Evardo Rocha.In: ROCHA,Everardo P. Guimarães. Magia e Capitalismo: um estudo antropológico da publicidade. 3.ed. 1.reimpr. São Paulo: Brasiliense, 2001. p. 7-18.

FERNANDES, Rubem César (Coord.). Novo Nascimento: Os Evangélicos em Casa, na Igreja e na Política. Rio de Janeiro: ISER, 1996. 
GEERTZ, Clifford. Nova Luz sobre a Antropologia. Rio de Janeiro: Jorge Zahar Editor, 2001.

LEACH, Edmund R. Culturae Comunicação: A lógica pela qual os símbolos estão ligados. Rio de Janeiro: Zahar Editores, 1978.

LOETZ, Claudio.Pesquisa AN/Maparevela que catarinenseconsidera ainda capacidade política e exemplos para definir o voto. A Notícia. Joinville. 28 de jul. 1998. Disponível em: http://www.an.com.br/1998/jul/28/0pot.htm. Acesso em: 20 de set. 2004.

MACHADO, Maria das Dores Campos. Existe um estilo evangélico de fazer política? In: BIRMAN, Patrícia (Org.). Religião e Espaço Público. São Paulo: Attar, 2003. p. 283-308.

MARINHEIRO, Vaguinaldo. Comentário: Pitta ainda é prefeito, e a culpa é sua. Folha Online. São Paulo. 12 de jul. 2000. Disponível em: http:// www1.folha.uol.com.br/folha/cotidiano/ult95u4607.shl.Acesso em: 20 de nov. 2004.

ORO, Ari Pedro. Neopentecostalismo: dinheiro e magia. ILHA - Revista de Antropologia, Florianópolis, v. 3, n. 1, p. 71-86, nov. 2001 a.

ORO, Ari Pedro. Religião e política nas eleições 2000 em Porto Alegre (RS). Debates do NER, Porto Alegre, v. 2, n. 3, p. 9-71, set. 2001 b.

PIERUCCI, Antônio Flávio. O Desencantamento do Mundo: todos os passos do conceito em Max Weber. São Paulo: Editora 34, 2003.

SEGALAN, Martine. Ritos e Rituais Contemporâneos. Rio de Janeiro: FGV, 2002.

SOUZA, Jessé. A Ética Protestante e a Ideologia do Atraso Brasileiro. In: SOUZA, Jessé (Org.). O Malandro e o Protestante: a tese weberiana e a singularidade cultural brasileira. Brasília: UnB, 1999. p. 17-54.

STEIL, Carlos Alberto. Eleições, voto e instituição religiosa. Debates do NER, Porto Alegre, v. 2, n. 3, p. 73-86, set. 2001. 